\title{
DIMENSÃO AXIOLÓGICA DO DIREITO: VALORES NO MULTIVERSO JURÍDICO
}

Fabiana Vergílio Souto, Israel Matheus Cardozo Silva Coutini, Thais Fernanda Silva Rogério, Ana Augusta Rodrigues Westin Ebaid.

Universidade do Oeste Paulista - UNOESTE, Curso de Direito, Presidente Prudente, SP. E-mail: fabianavergiliosouto@hotmail.com.

\section{RESUMO}

Esta obra tratou da incidência dos valores na construção do Direito e na sua aplicabilidade. A pesquisa se justifica, pela necessidade de se relacionar o Direito, que zela pelo bem comum com os valores que amoldam a conduta humana, servindo, emblematicamente, como um tipo de vetor condicionante dos fatos e normas, objetivando, com isso, não os apartar, mas sim, integrá-los.

A realização deste estudo, acerca do tema, é admitida e viável, visto que se vivencia, a todo instante, a "balança imaginária", que pesa os valores que se cultivam, como uma espécie de impulso natural, enquadrando fatos no conceito de adequado e inadequado. A presente pesquisa se utilizou de mecanismos, para dar-lhe seguimento e fundamentação teórica, valendo-se, em grande parte, da busca de material bibliográfico, mais especificamente livros escritos, e do formato digital, dando-se maior ênfase às doutrinas e aos autores renomados.

Palavras-chave: Dimensão Axiológica do Direito, Filosofia Jurídica, Moralidade, Positivismo, Valores.

\section{DIMENSION OF LAW AXIOLOGICAL: VALUES IN LEGAL MULTIVERSE}

\begin{abstract}
This work dealt with the impact of values in the construction of the law and its applicability. The research is justified by the need to relate the law, cares for the common good with the values that shape human behavior, serving, emblematically, as a kind of condition vector of facts and rules, in order, therefore, not separate the but integrate them. This study, on the subject, is admitted and viable, as is experienced, all the time, the "imaginary balance", weighing the values that are grown, as a kind of natural impulse, framing facts in the appropriate concept and inadequate. This research was used mechanisms to deal with it and theoretical basis, drawing on largely, the search for bibliographical material, specifically written books, and digital format, giving greater emphasis to the doctrines and renowned authors.
\end{abstract}

Keywords: Axiological Dimension of Law, Legal Philosophy, Morality, Positivism, Values. 


\section{INTRODUÇÃO}

$\mathrm{Na}$ assídua análise do fenômeno jurídico em sua complexa estrutura, certamente são encontrados valores sociais que condicionam, no Poder Legislativo, o interesse e a necessidade da sua inclusão no ordenamento jurídico. Por sua vez, a sociedade cultiva determinados valores que determinarão a ideia de justiça e injustiça diante da aplicação das leis.

O Direito não se interpreta por si só. Sendo assim, para ser aplicado, deverá ser interpretado. E, para que isso ocorra, é indispensável vinculá-lo a valores. A interpretação axiológica guia a interpretação jurídica. O objetivo central foi expor-se o valor, no contexto axiológico, como um dado cultural condicionador na veiculação do direito, esboçando a evolução histórica deste, por meio das teorias de autores expressivos acerca do tema: Hans Kelsen, Herbert Hart, Ronald Dworkin e Miguel Reale.

\section{INTERPRETAÇÃO DAS NORMAS E INCIDÊNCIA AXIOLÓGICA: PENSAMENTO KELSENIANO}

De acordo com Kelsen (1998, p. 18), "Quando uma norma estatui uma determinada conduta como devida (no sentido de "prescrita"), a conduta real (fática) pode corresponder à norma ou contrariá-la". Têm-se, então, dois valores que se contrapõem: o valor de lícito, que é um juízo de valor positivo; e o oposto, que remete ao que deveria ser segundo a norma jurídica, mas que não é, logo, ilícito, um juízo de valor negativo. Ainda, segundo Kelsen (1998, p. 19),

Na medida em que as normas que constituem o fundamento dos juízos de valor são estabelecidas por atos de vontade humana, e não de uma vontade supra-humana, os valores através delas constituídos são arbitrários. Através de outros atos de vontade humana podem ser produzidas outras normas, contrárias às primeiras, que constituem outros valores que estas constituem. (sic)

Apresenta-se, ainda, uma espécie de arquétipo sobre como a norma jurídica deve ser interpretada. A "moldura interpretativa" foi idealizada, justamente para resolver as intempéries nos casos de indeterminação jurídica. "O Direito a aplicar forma, em todas essas hipóteses, uma moldura dentro da qual existem várias hipóteses de aplicação, pelo que é conforme ao Direito todo ato que se mantenha dentro deste quadro ou moldura" (KELSEN, p. 390).

Diante disto, a norma superior compõe uma moldura dentro da qual haverá inúmeras possibilidades de aplicação do direito em relação às normas inferiores. No primeiro momento, o órgão aplicador se posicionaria neutro, apenas num ato cognoscitivo, conhecendo as possibilidades presentes dentro da moldura. $\mathrm{E}$, posteriormente, a partir de um ato volitivo, o órgão julgador optaria por uma das possibilidades e aplicaria o direito realmente. ${ }^{1}$

A concepção kelseniana distanciava qualquer influência de valores na aplicabilidade do Direito, o que implica a pureza e o positivismo jurídico. Logo,

a grande preocupação de Kelsen é construir uma ciência do Direito que tenha um

objeto puro, livre de qualquer contaminação ideológica, política, econômica etc., essencialmente jurídico e, como tal, passível de ser identificado sem maiores

dificuldades (MARQUES NETO, 2001, p.163). (sic)

Desse modo, seria ideal (e ilusório), se a realidade jurídica fosse modelada de acordo com a teoria de imparcialidade idealizada e proposta por Hans Kelsen. ${ }^{2}$ Contudo, totalmente o oposto disto, o julgador, como todos sabem, não é programado como um computador ou sistema de

\footnotetext{
${ }^{1}$ Unicamente sobre a base de uma clara compreensão das relações que constituem um ordenamento jurídico, pode-se entender plenamente a natureza do Direito (KELSEN, 1979, p. 3).

${ }^{2} \mathrm{O}$ próprio Kelsen afirma que sua intenção é atingir a teoria pura por meio de um método puro, reconhecendo que o Direito em si não é puro, tãosomente a teoria do Direito pode ser considerada pura. (KELSEN, 1986, p.56).
} 
inteligência computadorizada; a sua mente também comporta um turbilhão de valores, componentes dos seus princípios e ideologia. É natural tomar-se posição diante dos fatos, sendo impossível manter-se totalmente imparcial frente aos acontecimentos.

\section{COERSÃO LEGAL E MORALIDADE: PENSAMENTO HARTIANO}

Apartando Direito e Moral, os indivíduos manteriam um convívio adequado e equilibrado? Tais indivíduos seguiriam normas juridicamente válidas, mesmo se não houvesse ninguém os olhando, afastados dos olhos do Estado? Ensina, Hart (1987, p. 31):

A resposta a esta pergunta é, objetivamente, sim, o que não implica, de modo algum, que uma resposta também afirmativa não possa ser dada à pergunta inversa. [...] a Moral foi determinando o curso do Direito, algumas vezes furtiva e lentamente, informando o processo judicial; algumas vezes, ostensiva e abruptamente, influindo na via legislativa.

Hipoteticamente, a Moral é o que reveste o ser humano, é o que o torna visível. Vendo e sendo visto, fiscaliza seus próprios atos diante de valores que se contrapõem (bom e mau, lícito e ilícito etc.) e é fiscalizado por toda a sociedade, na qual está imerso. Se a Moral inexiste, o indivíduo torna-se invisível. E a problemática que surge é: seria o Direito autossuficiente, para preservar a ordem social? Sem freios morais, a administração dos atos volitivos, perante conflitos de valores, seria afetada. Destarte, a ordem social também.

Hart (1987, p. 44) deixa evidente a moralidade atrelada ao direito, quando salienta "[...] a preocupação em se considerar como moralmente certa e adequada a coerção exercida pelo meio legal, visando à subordinação de todos à moralidade aceita."

Segundo Devlin (apud HART, 1987, p. 56), "[...] a função do Direito criminal é impor um princípio moral, e nada mais.". Seria extremamente radical afirmar isto nos dias atuais. Em contrapartida, emblematicamente citando o Direito Criminal, ressalva Hart (1987, p. 57):

O fornecimento de drogas ou substancia entorpecente, sem autorização ou em desacordo com determinação médica, é considerado uma infração penal, e pareceria muito dogmático dizer que "existe apenas uma explicação", isto é, que a lei não estava preocupada com a proteção dos usuários contra eles mesmos, mas apenas com a punição dos traficantes, em razão da imoralidade destes. [...] Em nenhum caso, estamos obrigados a concordar com Lorde Devlin de que a "função" da lei seja "impor um princípio moral, e nada mais". (sic)

A contrariedade ao valor de lícito, ou seja, ilícito, só pode ser analisada e tratada pelo Estado, pois somente este tem poder jurisdicional, o poder-dever de dirimir conflitos, o ius puniendi, e escopo de zelar pelo bem comum. O Estado deve exercer seu poder sobre o valor negativo de ilicitude, porém não cabe a ele punir pela mera imoralidade, por mais que também seja um valor negativo. "O único motivo pelo qual o poder pode ser corretamente exercido sobre qualquer membro de uma comunidade civilizada contra a sua vontade é para impedir que ele cause mal aos outros" (MILL, 1859 apud HART, 1987, p. 33).

Resta clara a incidência da Moral sobre a construção do Direito, porém não será de bom tom afirmar-se que aquilo considerado imoral deve ser punido como ilícito. A moralidade servirá, mais, como uma unidade de medida, para medir o bom senso, o tolerável segundo dada sociedade e em determinada época, porém não equiparar ato imoral a ato ilícito, uma vez que são valores distintos, que podem coexistir, desde que separadamente. O conceito de moral não é ad eternum, é cíclico. 
Das argumentações de Herbert Hart, nota-se que é reconhecida claramente a incidência do que chamou de "moralidade positiva", 3 em âmbito social, porém jamais no âmbito jurídico. Coligese que o considerado inaceitável é o que o mesmo denominou "legalização da moral", ${ }^{4}$ o que significa a possibilidade de prescrição de determinados valores por vias jurídicas, considerando-se que deve sempre haver rígidas restrições de intervenção do Direito na liberdade de cada indivíduo.

\section{OS VALORES NA FILOSOFIA LIBERAL DO DIREITO: PENSAMENTO DWORKINIANO}

Ronald Dworkin buscou desenvolver métodos interpretativos, para potencializar, positivamente, a aplicabilidade do Direito nos casos concretos, ou seja, a subsunção. Buscou elaborar uma filosofia liberal do Direito, preocupando-se, acima de tudo, com o princípio da igualdade, remetendo-o ao entendimento moral de que, na própria igualdade que tanto se espera o limite que deve ser imposto à liberdade coletiva, ${ }^{5}$ ou seja, de toda a sociedade na qual o ser humano está imerso.

O pensamento dworkiniano evidentemente se opõe ao positivismo, fazendo críticas ao pensamento hartiano, partindo da hipótese de que o Direito é interpretativo, de maneira que os juízes devem decidir o que é o direito, interpretando-o. Assim, teorias gerais do Direito são, na realidade, interpretações gerais da própria prática judicial (DWORKIN, 1999, p. 488).

Em relação aos princípios, segundo o autor aqui tratado, apenas constitui um forte argumento, para que a decisão seja tomada em um determinado sentido. Diversamente das regras, os princípios podem convergir entre si, de tal forma, que, em determinado caso, um pode prevalecer sobre o outro, sem que qualquer deles seja eliminado do sistema. ${ }^{6}$

Sobre a distinção indispensável que deve ser feita entre princípios relacionados aos valores e regras relacionadas ao Direito, assevera Dworkin (2002, p. 43):

Quando os princípios se intercruzam, aquele que vai resolver o conflito tem que levar em conta a força relativa de cada um. Esta não pode ser, por certo, uma mensuração exata e o julgamento que determina que um princípio ou uma política particular é mais importante que outra frequentemente será objeto de controvérsia. (...) Se duas regras entram em conflito, uma delas não pode ser válida. A decisão de saber qual é válida e qual deve ser abandonada ou refutada deve ser tomada, recorrendo-se a considerações que estão além das próprias regras. (sic)

Segundo o seu entendimento, as regras funcionam, seguindo uma "lógica do tudo ou nada", enquanto os princípios fluem de acordo com a "lógica do mais ou menos", pois comportam maior flexibilização no momento de influir em implicações jurídicas.

Dworkin trata o Direito como integridade, procura trazer, para o debate, a sua crítica ao positivismo jurídico e a defesa de uma teoria liberal do direito, realizando uma interpretação chamada constitutiva do Direito. Salienta a importância dos princípios em termos valorativos, vez que um potencializa o outro no momento de fazer a subsunção; ou seja, mesmo que apenas um princípio seja abordado na decisão, não exclui os demais, pois de certa forma fortalecem o princípio mais adequado. Por outro lado, as regras têm um caráter unitário. Quando somente uma é adequada, significa, automaticamente que todas as outras não o são.

Os princípios têm uma extensão valorativa, são de tamanha relevância, a ponto de cada um deles poder influenciar a decisão. Cada qual é ponderado e, posteriormente, o julgador deverá

\footnotetext{
${ }^{3}$ Conjunto de condutas, convicções históricas e comportamentos que pautam um estilo de convívio humano considerado moralmente correto em determinada sociedade.

${ }^{4}$ Inclusão da "moralidade positiva" nas leis, ou seja, as normas jurídicas incorporariam valores.

${ }^{5} \mathrm{Cf}$. Dworkin, em sua obra "Domínio da Vida" trata do resplandecente valor da vida humana, fazendo importante alusão à dignidade humana.

${ }^{6}$ Cf. O grande objetivo de Dworkin na obra "Levando os direitos a sério" foi fazer um ataque ao Positivismo (general attack on Positivism) 
escolher qual deles irá prevalecer, sem que os demais percam sua potência em virtude de tal preferência. Fluentemente, segundo o pensamento dworkiniano, mais especificamente a teoria proposta na obra "O Império do Direito", essa seleção entre princípios deveria concretizar-se na prática jurídica cotidiana, iluminada pelo sol da Justiça e pela luz transcendente dos valores positivos atinente a cada princípio.

\section{VALORES COMO ELEMENTOS VOLITIVOS CONDICIONANTES DOS ATOS HUMANOS: PENSAMENTO REALIANO}

Segundo Reale (2002, p. 37), "Cada homem é guiado, em sua existência, pelo primado de determinado valor, pela supremacia de um foco de estimativa que dá sentido à sua concepção da vida." Significa que o juízo concebido sobre determinado valor é essencial para traçar os ideais de alguém, especialmente porque a tudo que conspira culturalmente se atribui valor.

Na teoria realiana, no que se refere à Filosofia do Direito, o problema nuclear é o valor do justo e que o estudo de tal conteúdo está atrelado à determinação da consistência da realidade jurídica, ocasionando problemáticas no concernente às estruturas dos juízos jurídico-normativos (REALE, 2002, p. 38). Diante disto, o valor do justo parece ser conditio sine qua non para a construção ou estruturação do Direito.

Diz o ilustríssimo Reale (2002, p. 379):

A ação, em seu sentido rigoroso, ou o ato, é energia dirigida para algo que é sempre um valor. O valor, portanto, é aquilo a que a ação humana tende, porque se reconhece, em um determinado momento, ser motivo, positivo ou negativo da ação mesma, [...] toda vez que o homem atua, objetiva ou contraria algo de valioso. (sic)

Significa, então, que conforme o ser humano atua, é sempre motivado por um valor que norteia sua vontade de agir. "Os homens não se vinculam, em seu agir, apenas por valores de transcendência, mas também se ligam por algo que está neles mesmos ou, então, nos outros homens" (REALE, 2002, p. 396).

Isto quer dizer que não são apenas os valores estimados pela sociedade ou grupo majoritário que norteiam o homem, são, também, os valores que apenas ele estima ou que um grupo minoritário cultue como realmente valioso.

No que se refere à moral e à conduta humana em sociedade, demonstra Reale $(2002, \mathrm{p}$. 396): "O que distingue a conduta moral é esta pertinência da estimativa ao sujeito mesmo da ação. De certa forma poder-se-ia dizer que, no plano da conduta moral, o homem tende a ser o legislador de si mesmo." Quer dizer que o homem elabora seus próprios preceitos, suas próprias regras de conduta, baseando-se nos valores que considera positivos. Analogamente, cada um "legisla", criando suas próprias normas de conduta, e fica sujeito ao julgamento dos demais segundo os princípios e valores tidos como positivos destes.

Ainda neste sentido, salienta Reale (2002, p. 397):

No comum dos atos morais, vive-se a regra em seu sentido pleno e espontâneo, tal como se oferece na riqueza de seus motivos e atrações. [...] A Moral é incompatível com qualquer ideia ou plano de natureza coercitiva, quer de ordem física, quer de ordem psíquica. [...] No ato moral, é essencial a espontaneidade, de tal maneira que a educação para o bem tem de ser sempre, uma transmissibilidade espontânea de valores, uma adesão ao valioso, que não implica nenhuma subordinação que violente a vontade ou a personalidade. (sic) 
O autor deixa evidente que a moralidade e seu poder, sobre as relações humanas, devem ser espontâneos, ou seja, transmissíveis por atos de vontade. Assim, não incidiria a coerção, como se o que é moral devesse ser obrigatoriamente seguido. Ou, ainda, aquilo considerado imoral, devesse ser repudiado por meio de medidas coercitivas, fato que o Estado não pode apenar.

Assim, o ente estatal tem o poder-dever de repreender condutas ilícitas, porém a moralidade não está sob sua tutela, não lhe cabendo a função de enquadrar as condutas humanas em conceitos já pré-elaborados.

$E$, se ainda restam dúvidas de que os valores constroem o Direito e influenciam a sua aplicabilidade, basta verificar-se a diversidade jurisprudencial e as contraposições doutrinárias, onde há inúmeras posições divergentes, que remetem à heterogeneidade ideológica da sociedade, sendo exatamente isto que impulsiona o Direito a acompanhar as demandas conforme o dinamismo ideológico social.

Ressalta-se aqui, o valor alfa do Direito, o valor do justo, que é componente, por sua vez, de inúmeros princípios e ideologias, tais como isonomia e liberdade.

Muito próximo do pensamento realiano, produz, antologicamente, Paupério (1977, p.121): "De certo modo, o Direito não se pode compreender senão no círculo de comportamento impregnado de valor".

\section{CONCLUSÃO}

Apresenta-se que os valores ou bússolas de valor, moldam as mais diversas possibilidades de convívio do ser humano em sociedade, considerando-se que ubi societas ibis jus, não apenas no sentido estrito-jurídico, mas em sentido amplo, de qualquer forma de regra que contribua para o convívio viável dos indivíduos em sociedade, ou seja, pacificamente. Basicamente, os valores são elementos culturais e, como as bússolas de valor, são desenvolvidos pelas civilizações, justamente para facilitar o convívio social, almejando adotar formas de vida melhores, mais justas e adequadas. Os valores se alteram, conforme as gerações se sucedem, e as mesmas são responsáveis pela alteração de tais valores, uma vez que criticam, no que consideram necessário, e os reconstroem conforme tais críticas e da forma como for conveniente.

Destarte, com o presente trabalho que esboçou, cronologicamente, a evolução e o amadurecimento da concepção acerca do conceito de valor, e principalmente a sua aceitação dentro do multiverso jurídico, tem-se a noção de que o Direito não se interpreta por si só, e, para que seja aplicado, deve ser interpretado. Para que isto ocorra, é indispensável vinculá-lo a valores. A interpretação axiológica guia a aplicabilidade do Direito e este, sendo aplicado a contento, em conformidade com o ideal de Justiça, é a coluna dorsal de uma sociedade justa e pacífica.

\section{REFERÊNCIAS}

CANARIS, Claus-Wilhelm. Pensamento sistemático e conceito de sistema na ciência do Direito. Trad. Menezes Cordeiro. 3. ed. Lisboa: Fundação Calouste Gulbenkian, 2002.

DIMOULIS, D. Positivismo jurídico: introdução a uma teoria do direito e defesa do pragmatismo jurídico-político. São Paulo: Método, 2006.

DWORKIN, Ronald. Levando os direitos a sério. Trad. Nelson Boeira. 3. ed. São Paulo: Martins Fontes, 2010.

1999.

. O Império do Direito. Trad. Jefferson Luiz Camargo. 1. ed. São Paulo: Martins Fontes, . Uma Questão de Princípio. Trad. Luís Carlos Borges. São Paulo, Martins Fontes, 2000.

HART, Herbert. Direito, Liberdade, Moralidade. Trad. De Gérson Pereira dos Santos. Porto Alegre: Fabris, 1987. 
KELSEN, Hans. Teoria Pura do Direito. Trad. João Baptista Machado. 6. ed. São Paulo: Martins Fontes, 1998.

. Teoria geral das normas. Trad. José Florentino Duarte. Porto Alegre: Fabris, 1986. Teoría general del derecho y del Estado. Trad. García Maynez. México: UNAM,

1979.

MARQUES NETO, Agostinho Ramalho. A ciência do Direito: conceito, objeto, método. 2.

ed. Rio de Janeiro: Renovar, 2001.

PAUPÉRIO, Arthur Machado. Introdução axiológica do Direito. Rio de Janeiro: Forense, 1977.

REALE, Miguel. Filosofia do Direito. 20. ed. São Paulo: Saraiva, 2002. . Lições Preliminares do Direito. 26. ed. São Paulo: Saraiva, 2002.

VASCONCELOS, Arnaldo. Direito, Humanismo e Democracia. 3. ed. São Paulo: Malheiros, 1998. . Teoria Pura do Direito: repasse crítico de seus principais fundamentos. Rio de

Janeiro: Forense, 2003. 